Coastal Hydraulics 


\section{Coastal Hydraulics}

A. M. Muir Wood, M.A., F.I.C.E., F.G.S.

Sir William Halcrow \& Partners

Macmillan Education 
@ A. M. Muir Wood 1969

Softcover reprint of the hardcover 1st edition 1969

First Published in 1969

Published by

MACMILLAN AND CO LTD

Little Essex Street London wc2

and also at Bombay Calcutta and Madras

Macmillan South Africa (Publishers) Pty Ltd Johannesburg

The Macmillan Company of Australia Pty Ltd Melbourne

The Macmillan Company of Canada Ltd Toronto Gill and Macmillan Ltd, Dublin

ISBN 978-1-349-00426-3 ISBN 978-1-349-00424-9 (eBook) DOI 10.1007/978-1-349-00424-9 


\section{Preface}

The young engineer tends to find Hydraulics a bewildering subject; the initial coherent discipline in applied mathematics which he was taught at college appears, when pursued further, to disintegrate in practice into unrelated - and sometimes dimensionally unbalanced - empirical formulae. Nowhere is this dichotomy more in evidence than in the dynamics of the sea.

The processes of checking theory against practice and setting limits on the applicability of theories have proceeded slowly in marine hydraulics for two reasons: first, the sheer complexity of the various natural forces is resistant to separation into components for analysis; second, there has been a lag in collecting experimental data at sea. These two aspects are very much interrelated. A large amount of evidence is necessary to explore the contribution of any one factor, particularly in extreme conditions of tide and weather; only recently has it been possible to obtain comprehensive instrumented data in these conditions, which are of primary engineering interest. A further difficulty lies in the irregular boundaries of the sea which require the analysis of problems of coastal hydraulics to be based on three-dimensional models (hydraulic, analog or conceptual) with time as a fourth variable. Energy transfer and losses at the sea boundaries are only partially understood; hence, waves and currents, which are responsible for the main problems of coastal hydrodynamics, are not wholly explicable by analysis.

The problem of relating theory to practice is central to the purpose of this book. The limitations on the use of a particular wave theory, for instance, are most readily understood by a knowledge of the assumptions and approximations which enter into its derivation. It is found frequently to be simpler to extend theory on the basis of an empirical study than to adopt a more complicated theory at the outset. There are several reasons why the coastal engineer has to be able to use the simplest approach to the solution of a problem. He is often faced with alternative schemes for 
meeting a given set of conditions and the choice of scheme may be based on a fairly elementary study. In addition, many marine problems have to be solved with an imperfect knowledge of relevant factors. Too complicated an approach may make it difficult subsequently to separate the effects of the 'knowns' and the 'guestimates', as must be done to test whether the method provides a solution of sufficient accuracy.

While, in many fields of engineering, the availability of the computer reduces the merit of simplicity, the margin of uncertainty attached to many data in coastal engineering renders dangerous the air of verisimilitude that surrounds an overprecise mathematical solution. But it should be emphasized that computer methods represent the only practical approach to specific problems of propagation of tidal waves and currents in shallow water. Computers are also successfully and economically invading fields of wave refraction, reflection and dissipation, currently tackled by the hydraulic model.

Certain theories in marine hydraulics cannot be developed far enough to provide full solutions but an appreciation of their physical significance will lead to a helpful insight into the probable validity of extrapolation of experimental results. In some instances, experiment serves to evaluate 'variable constants' which are then used in the correct theoretical form of a relationship.

The most valuable experimental work has been carried out by those with a firm grasp of the underlying physical concepts; this proposition is exemplified in Britain by the work of Osborne Reynolds in the last century and Brigadier Bagnold at the present day. It seems unfortunate that a high proportion of experimental work on waves and beaches, in particular, has been carried out by geographers who are not equipped to analyse the problem for study and whose results, in consequence, are of little more than descriptive value.

The coastal engineer's designs are frequently related to extreme conditions, representing the most unfavourable combination of different factors. Each factor is described in statistical terms and a fully statistical approach would calculate the probability of a certain condition on the assumption that all contributory factors are independent. In fact, they are to some extent related and the probability pattern is affected in consequence. There is need here for patient studies in the collection of data and in isolating the effects of each factor.

Many of the empirical relationships used in coastal hydraulics have been derived from study of hydraulic models. Caution is then needed in two respects: first, it is necessary to ensure that the model adequately represents the prototype and an example here is provided by the different results that may be obtained from models of breaking waves, with the use 
of regular and irregular wave trains; second, it is necessary either to ensure adequate dynamic similarity or to be able to correct the results to take account of varying scale factors. Arbitrary roughening of a model to represent a prototype entails limited validity in reproducing changes in the prototype.

The coastal engineer relies upon the oceanographer for the provision of information on the characteristics of deep water waves. Virtually all the data on the characteristics of waves at sea have been obtained during the last thirty years. During the second world war, the use of assault landing craft required the ability to forecast waves in a given situation for a known weather pattern and, also, to predict their modification by shoaling water. Many of the subsequent studies on waves have grown from the teams assembled at this time, and in Britain this work led to the creation of the National Institute of Oceanography.

Where the problem concerns coastal morphology or the pattern of siltation and scour at sea, the engineer should not overlook the importance of geological factors. It is necessary to stress that this book excludes such considerations. In certain localities, the design of the optimum scheme of coastal engineering or harbour works may be closely dictated by the geological structure or the more recent evolution of the coast and the seabed off-shore.

During the preparation of this book I have received valuable criticism from my colleagues, E. Loewy and C. J. Antonakis. I also wish to acknowledge the numerous constructive suggestions made by Dr. E. M. Wilson, the editor of the series. I have had welcome assistance, in editing the text and preparing the figures, from my sons P. M. W., D. M.W. and R. M.W. Finally, I have to thank Mrs. Angela Larard for her part in the successful preparation of drafts of the text from an inscrutable manuscript. 


\section{Contents}

Preface V v

1 Tides and currents 1

1.1 The equilibrium tide

1.2 Dynamic modifications of the equilibrium tide

1.3 Modification of tidal pattern

1.4 Tidal streams

1.5 The sea surface as a levelling datum

1.6 Tidal bores

2 Waves

2.1 The linear theory of waves

2.2 Waves of finite height

2.3 Wind waves

2.4 Waves in shoaling water

2.5 Refraction of waves

2.6 Reflection of waves

2.7 Diffraction of waves

2.8 Oscillations in a harbour

2.9 Ship waves

3 Movement of material by the sea

3.1 Material in suspension

3.2 Bed-Load 
3.3 Turbidity and density currents

3.4 Banks and channels in river estuaries

3.5 Regime of the sea-bed

4 Littoral drift

4.1 Definition of limit for littoral drift

4.2 The effect of grain size

4.3 The beach profile

4.4 Longshore transport of material

4.5 Coastal features

5 Planning of coast protection

5.1 The natural beach

5.2 Layout of groynes

5.3 Seawalls and parallel revetments

5.4 Beach replenishment

5.5 Directions of approach of waves to the shore

6 Waves and structures

6.1 Selection of the design wave

6.2 The continuous vertical wall

6.3 Dissipation of wave energy

6.4 Wave forces on cylinders

7 The acquisition of data

7.1 Current measurements

7.2 Wave measurements

7.3 Hydrographic surveys

7.4 Measurement of sediment movement

7.5 Measurement of littoral drift

Notation 


\section{List of Plates}

1 'The Wave'

facing page

Photo: Ander Gunn

2 Severn Bore

Photo: F. W. Rowbotham

3 Long Swell at Achill Island, Co. Mayo

Photo: Jon Bennett

4 Spilling Breaker, Caithness

Photo: R. G. Jacobs

5 Wave Refraction in North Bay, Scarborough

Photo: B. Goss

6 Wave breaking on inclined wall, Porthcawl, Glam.

Photo: J. I. Levi

7 Wave reflection and refraction in model test for Tema fishing harbour

Photo: Hydraulics Research Station, Wallingford (Crown copyright reserved)

8 Miniature beach cusps, Seaford

9 Dungeness Foreland, looking north

Photo: J. K. St. Joseph, Cambridge University Collection (Copyright reserved)

10 Hurst Castle and Spit, Hants, looking north-west

Photo: J. K. St. Joseph, Cambridge University Collection (Copyright reserved)

11 Revetment in Tripod Units, Seaford

Photo: A. H. Toms 
12 Stabit Armoured Breakwater, Benghazi

13 Kish Bank Lighthouse

Photo: B. Levy 